\title{
O IMPACTO DO PROJETO COSMOS NA FORMAÇÃO CIENTÍFICA DOS ESTUDANTES DE ENSINO BÁSICO PARA AS OLIMPÍADAS DE ASTRONOMIA
}

\author{
THE IMPACTO OF THE COSMOS PROJECT ON THE SCIENTIFIC TRAINING \\ OF BASIC EDUCATION STUDENTS FOR THE ASTRONOMY OLYMPICS
}

\author{
Alexsandro Moraes de Brito ${ }^{1}$ \\ Antonio Xavier Gil ${ }^{2}$
}

RESUMO: Esta pesquisa teve como objetivo geral analisar o impacto do Projeto Cosmos na formação científica dos estudantes do ensino básico nas olimpíadas de astronomia. Desta forma, traçou-se os seguintes objetivos específicos: identificar quais os conhecimentos científicos sobre astronomia que os estudantes possuíam antes de ingressarem no preparatório do Projeto Cosmos; verificar a forma com que o Projeto Cosmos vem trabalhando com os estudantes para as olimpíadas de astronomia; avaliar os conhecimentos científicos adquiridos pelos estudantes após as atividades preparatórias do Projeto Cosmos para as olimpíadas de astronomia; e analisar as percepções dos participantes sobre a atuação do Projeto Cosmos que indique o seu impacto. Em vista disto foi realizada a coleta de dados com os seguintes instrumentos: questionário estruturado direcionado aos estudantes na etapa inicial e na final do preparatório, com perguntas de múltipla escolha sobre conceitos de astronomia de modo remoto, observações e entrevistas direcionadas aos coordenadores do projeto e aos monitores-professores sobre as atividades do Projeto Cosmos, e por fim, dois questionários com perguntas abertas e fechadas direcionadas aos alunos no início e no fim do preparatório. E, o tratamento dos dados foram através das análises dos resultados dos Questionários; análise de conteúdo das entrevistas, além de uma Análise descritiva da pesquisa. Traz como contribuição científica o registro do impacto do Projeto Cosmos na formação de conceito científicos no preparatório para as olimpíadas de Astronomia. Os resultados alcançamos, mostraram que o projeto cosmos teve um impacto muito grande na formação dos conceitos de astronomia dos estudantes do ensino fundamental $e$ médio da cidade de Manaus, com uma metodologia teórica e prática de aulas a cada semana, que deram destaques e projetaram os alunos na participação das olimpíadas, inclusive com ganho de medalhas. Tendo uma boa percepção por parte dos alunos que foram motivados a continuar estudando sobre Astronomia.

Palavras-chaves: Astronomia. Metodologia de Ensino. Projeto Cosmos.

\footnotetext{
${ }^{\mathrm{I}}$ Discente no curso de licenciatura plena em física e bolsista no Programa de Iniciação Científica (PIBIC) pela Universidade Federal do A mazonas- UFAM.

2 Doutor em fundamentos e métodos na Educação em Ciências e Matemática, Pesquisador da Universidade Federal do Amazonas e líder do Grupo ECIMATH, e atualmente orienta alunos de Mestrado, Graduação e PIBIC. E-mail: xavier2oogxavier@gmail.com
} 
ABSTRACT: This research had as general objective to analyze the impacto $f$ the Cosmos Project in the scientific formation of the students of the basic education in the astronomy olympics. In this way, the following specific objectives followed: to identify what scientific knowledge about astronomy the students had before entering the preparations for the Cosmos Project; verify the way that the Cosmos Project has been working with students for the astronomy olympics. To evaluate the scientific knowledge acquired by the students after the preparatory activities of the Cosmos Project for the astronomy olimpics; and to analyze the participants' perceptions about the performance of the Cosmos Project that indicates its impact. In view of this, data collection was carried out with the following instruments: structured questionnaire addressed to students in the initial and final stages of the preparatory phase, with multiple choice questions on astronomy concepts remotely, observations and interviews directed to the Project coordinators and to the teachermonitors about the activities of the Cosmos Project, and finally, two questionnaires with open and closed questions directed to the students at the beginning and at the end of the preparatory. Therefore, the treatment of the data was through the analysis of the results of the questionnaires; analysis of the contente of the interviews, in addition to a descriptive analysis of the research. It brings as a scientific contribution the record of the impacto of the Cosmos Project in the formation of scientific concepts in the preparation for the Astronomy Olympics. The results we achieved showed that the Cosmos Project had a very big impacto on the formation of the Astronomy concepts of elementar and high school students in the city of Manaus, with a theoretical and practical methodology of classes Every week, which gave highlights and projected the students participating in the Olympics, including winning medals. Having a good perception on the parto $f$ the students who were motivated to continue studying about Astronomy.

Keywords: Astronomy. Teaching Methodology. Cosmos Project

\section{INTRODUÇÃO}

A vista do céu fascina a humanidade desde antes da escrita, além de que foi por muito tempo considerada uma fronteira inalcançável. Tendo como exemplo desta fascinação, a nossa grandiosa estrela Sol, que forma junto com mais oito planetas o sistema solar, e cujo fenômeno da propagação retilínea de seus raios de luz, tangenciando o planeta, resulta no dia e na noite. Quando a luz atravessa a atmosfera do planeta terra, temos uma visão da vastidão de área azul e branca, bem como uma tonalidade que vai do amarelo ao avermelhado, quando o sol se encontra na posição da linha do horizonte, ou seja, quando ele nasce ou se põe.

De acordo com Nogueira et al (2009, p. 20).

Basta notar que as noções básicas sobre o Sistema Solar são dadas nas aulas de geografia, as leis de movimentos dos planetas estão no curso de física, o 
andamento da corrida espacial no século 20 está na disciplina de história, e as descobertas mais sofisticadas sobre a origem do universo, pasmem, não estão em lugar algum.

Em vista disso, o Projeto Cosmos fez uso deste fascínio para divulgar Ciência em várias instituições de ensino público do Amazonas, Desde a sua criação em 2015, e ativação em 2017 como um Projeto de Extensão Universitária da Universidade Federal do Amazonas, até sua transformação em formato digital em 2020.

Então, umas das atividades realizadas pelo Projeto Cosmos, foi o Preparatório Cosmos, uma atividade desenvolvida anualmente com o intuito de ofertar um auxílio para exames das Olimpíadas Brasileira de Astronomia (OBA).

O Projeto Cosmos foi criado acreditando-se que a astronomia poderia servir como grande incentivo aos estudantes em diversas áreas das ciências, devido a sua característica interdisciplinar, atiçando as suas curiosidades, de forma que fosse possível aproveitá-la em várias disciplinas.

Como informado por Scarinci e Pacca (2005), ela é frequentemente presente apenas na ementa de geografia, durante o ensino fundamental, e o formalismo matemático e os conceitos físicos que sustentam os fenômenos são poucos discutidos.

Visto que o projeto em questão trabalha mediando conteúdos referentes ao tema com diversas oficinas, exemplificando situações práticas presentes no cotidiano, ocorre o seguinte problema científico: qual ou quais são os impactos do Projeto Cosmos na formação científica dos estudantes de Ensino Médio no preparo para as Olimpíadas de Astronomia? Como tal iniciativa afeta os alunos participantes e como ocorre?

Deste modo, esse raciocínio nos remete as seguintes questões norteadoras: que conhecimentos científicos os estudantes possuem no início do ingresso ao preparatório do Projeto Cosmos?; De que maneira o Projeto Cosmos vem preparando os estudantes para as Olimpíadas de Astronomia?; Que conhecimentos científicos os estudantes adquirem após as atividades preparatórias do Projeto Cosmos para as Olimpíadas de Astronomia?; Quais as percepções dos participantes sobre a atuação do Projeto Cosmos que indique o seu impacto? Todas essas e outras reflexões a respeito do funcionamento deste projeto de extensão é proposto para serem 
esclarecidas com essa pesquisa, adquirindo um maior entendimento da importância de ações similares e seus impactos na vida dos jovens e adolescentes no Amazonas.

\section{FUNDAMENTAÇÃO}

Os projetos de extensão são vistos na reflexão de alguns autores como uma oportunidade de divulgar a ciência mediante o compartilhamento do saber com a sociedade local. Segundo De Oliveira (2017), essa divulgação científica é vista como uma forma de popularização da ciência, a qual pode ser classificada como uma educação não formal que se utiliza de ferramentas pedagógicas, tal como a transposição didática que propicia um ensino mais descontraído e lúdico.

A questão crucial aqui é que os projetos de extensão acabam impactando a sociedade pelo ensino com a pesquisa, processo educativo e cultural que possibilita a relação transformadora da Universidade com a Sociedade (RODRIGUES, 2015).

É nessa troca de saberes, entre a comunidade e academia, que o conhecimento se fortalece e o ensino passa a ter uma aplicação prática e real para a comunidade, o que encontra a sua fundamentação em Paulo Freire (SERRANO, 20Io, p.II).

Na UFAM temos as seguintes modalidades de Extensão:

Programa de Atividade Curricular de Extensão (PACE) - E uma modalidade de ação extensionista que acompanha o semestre letivo.

Programa de Apoio à Realização de Cursos e Eventos (PAREC) - É o programa por meio do qual os eventos e cursos de extensão recebem apoio da Pró-Reitoria de Extensão e Interiorização (Proexti). Ele deve ser solicitado em fluxo contínuo por meio de formulários específicos.

Programa Institucional de Bolsas de Extensão (PIBEX) - Através desse programa, são oferecidas bolsas de extensão para cada projeto aprovado. As atividades podem ser semestrais ou anuais, de acordo com o edital do Programa.

$\mathrm{MEC} / \mathrm{SESu}$ - As ações propostas nessa modalidade são do Ministério da Educação (MEC). A Proexti/UFAM é responsável pela divulgação dos editais e pela seleção dos projetos, pela Câmara de Extensão, para concorrerem em nível nacional. Saiba mais sobre os editais divulgados pelo MEC.

Neste sentido o Projeto Cosmos é da Modalidade de Programa de Atividade Curricular de Extensão (PACE), cuja metodologia é de preparo dos estudantes para as Olimpíadas de 
Astronomia OBA, através de coordenadores e professores monitores, cujo impacto na sociedade local é objeto de nosso estudo.

\section{METODOLOGIA}

Esta pesquisa é de abordagem qualitativa, participativa e descritiva. E, os sujeitos ou participantes foram os estudantes do Preparatório do Projeto Cosmos. Mas, como o estudo se pautava em quais os impactos do Projeto Cosmos na formação dos estudantes do ensino básico para as olimpíadas de astronomia, então foram excluídos da amostra os que não estavam matriculados em instituições Públicas ou Privadas de Ensino Básico, e os que não estavam devidamente matriculados entre o $6^{\circ}$ ano do fundamental e o $3^{\circ}$ ano do Ensino Médio, bem como os portadores de necessidades especiais.

Deste modo, fez-se uma sondagem inicial para registrar os conhecimentos prévios dos estudantes, e uma sondagem final dos conhecimentos adquiridos, e uma coleta das percepções para avaliação do impacto do Projeto Cosmos; cuja obtenção de dados foi realizada utilizando-se os seguintes instrumentos de coleta de dados: questionário estruturado direcionado aos estudantes na etapa inicial e final do preparatório, com perguntas de múltipla escolha sobre conceitos de astronomia, observações e entrevistas direcionadas aos coordenadores do projeto e aos monitores-professores sobre as atividades do Projeto Cosmos, e por fim, um questionário com perguntas abertas e fechadas direcionadas aos alunos. E, o tratamento dos dados foi através da análise Comparativa dos resultados dos Questionários; análise de conteúdo das entrevistas, Mapas de associação de ideias das percepções sobre o projeto, Análise descritiva das observações, e uso de gráficos.

\section{RESULTADOS E ANÁLISES}

\section{a) Resultados do questionário inicial direcionado aos estudantes}

No questionário de expectativa: o impacto do projeto cosmos na formação científica dos estudantes do ensino básico para as olimpíadas de astronomia, a sua aplicação deveria ter sido em I4 de março de 2020, entretanto devido a pandemia, com o fechamento da UFAM, não foi possível pela paralisação do Projeto Cosmos, isso comprometeu a coleta de dados e consequentemente o cronograma, e o projeto em si, 
teve que ser adaptado para a coleta de dados de modo remoto. Neste sentido, tivemos que novamente submeter o projeto ao Comitê de Ética e aguardar pela aprovação para poder proceder a coleta de dados.

Para a coleta de dados de modo remoto, adaptamos o questionário que já tínhamos, e o reescrevemos no Google Formulários, para enviar aos alunos por email. Entretanto, como os alunos de 2020, não chegaram a ter aulas, devido a paralisação, foi adquirido uma relação de estudantes participantes do preparatório do projeto Cosmos do ano de 2019, para tentarmos dar seguimento com a pesquisa de modo remoto.

Neste sentido, com este propósito, solicitamos as permissões dos sujeitos enviando o termo de assentimento e o termo de consentimento livre e esclarecido, para a lista de e-mails dos estudantes de 2019, entretanto, somente 2 alunos deram retorno.

Em seguida, enviamos o questionário inicial direcionado aos estudantes, novamente por e-mail. Foram enviados os questionários para 2 turmas no turno matutino e 3 turmas no turno vespertino, uma turma com 24 alunos, outra com 13 alunos, outra também com 13 alunos, outra com i6 alunos, e a última também com i6 alunos. Entretanto, de todos esses alunos, somente os mesmos 2 alunos que deram retorno, os demais deram desculpas e explicações de que não participaram por diversos motivos, dos quais citamos: se escreveu, mas não participou; iniciou no projeto, mas desistiu; etc., e outros nem deram satisfação ou o contato de e-mail constava errado na relação de alunos das turmas.

Portanto, neste questionário inicial, quanto aos dados de identificação dos estudantes, e quanto ao:

I. Gênero - 50\% masculino, e $50 \%$ feminino;

II. Idade: Entre I4 a I6 anos;

III. Data de ingresso no projeto Cosmos: o9 de fevereiro de 2019.

IV. Escola que estuda: Escola Pública.

Quanto as perguntas direcionadas aos participantes, eles responderam nas questões:

I. Como soube do preparatório do Projeto Cosmos? 
$\mathrm{R}-50 \%$ Através de Mídia social e 50 \% através da casa da Física.

2. Por que se inscreveu no Preparatório do Projeto Cosmos?

$\mathrm{R}$ - $50 \%$ foi por curiosidade, e $50 \%$ por interesse em Astronomia.

3. Alguma vez você já participou das Olimpíadas Brasileira de Astronomia (OBA)?

$\mathrm{R}-50 \%$ já havia participado 2 vezes; e $50 \%$ nenhuma vez.

4. Estime o seu conhecimento a respeito da Astronomia?

$R$ - 50\% respondeu ser regular, e 50\% respondeu ser pouco.

5. Qual o grau de intensidade de seu interesse para estudar os assuntos elencados a seguir? Marque uma das intensidades de i a 5 , onde I é nenhum interesse, 2 é pouco interesse, 3 é médio interesse, 4 é bastante interesse e 5 é grande interesse.

História da astronomia; $\mathrm{R}$ - 50\% disseram ter médio interesse, e 50\% bastante interesse.

Constelações; $\mathrm{R}$ - 50\% respondeu ter pouco interesse e $50 \%$ respondeu ter bastante interesse.

Terra; $\mathrm{R}$ - 50\% relatou ter médio interesse, e 50\% disse ter bastante interesse.

Sistema Terra-Lua; $\mathrm{R}$ - $50 \%$ disse ter médio interesse, e 50\% respondeu ter bastante interesse.

Sistema Solar: $\mathrm{R}-50 \%$ disse ter pouco interesse, e 50\% relatou ter bastante interesse.

Gravidade: R - I00\% relataram ter bastante interesse.

Universo: $\mathrm{R}$ - 50\% respondeu ter médio interesse, e 50\% respondeu ter bastante interesse.

6. Que medalha você acredita ser capaz de conquistar na OBA XXIII?

$\mathrm{R}$ - I00\% responderam ser capazes de conquistar medalha de prata.

\section{b) Resultados do questionário inicial de conceitos direcionado aos estudantes}

Neste questionário apenas I dos sujeitos respondeu e nos enviou o formulário, o outro sujeito não nos deu retorno.

Portanto, as perguntas e respostas foram: 
I. Galileu Galilei foi um grande astrônomo, porém, por volta de I638 ele ficou cego. Que motivo ocasionou a lesão nos olhos de Galileu?

$R$ - O estudante respondeu que foi devido a observação do Sol. E esta é a resposta correta.

2. A Lua brilha no céu porque é iluminada pelo Sol. Em alguns dias do mês, por volta de 06:0o horas a Lua nasce, e às I2 horas da tarde alcança o zênite. Quando isso ocorre, a fase da Lua é

$\mathrm{R}$ - O estudante relatou não saber a resposta. $\mathrm{E}$, a resposta correta é Lua nova.

3. Qual constelação circumpolar visível sem auxílio de lentes ou instrumentos ópticos é referência para a localização dos pontos cardeais no hemisfério sul?

$\mathrm{R}$ - O estudante respondeu que a constelação é Cruzeiro do Sul. E esta é a resposta correta.

4. Qual é o elemento mais pesado que pode compor uma estrela durante sua existência?

$\mathrm{R}$ - O estudante disse que o elemento é o Ferro. E esta é a resposta correta.

5. O que causa o Efeito da Maré?

$\mathrm{R}$ - O estudante respondeu que a causa é devido a atração gravitacional do Sol e da Lua. E esta é a resposta correta.

6. Assinale a alternativa que indica apenas os planetas rochosos do sistema solar:

$\mathrm{R}$ - O estudante respondeu que é a alternativa 4 , contendo os planetas Mercúrio, Vênus, Terra e Marte. E esta é a resposta correta.

7. Entre pontos e planos importantes nos estudos da astronomia, temos o que representa o ponto mais alto acima de cada observador. Este ponto é:

$\mathrm{R}$ - O estudante respondeu que o ponto é chamado de zênite. E esta resposta está correta.

8. A respeito da vida das estrelas, qual destas alcança o maior tempo de existência?

$\mathrm{R}$ - O estudante respondeu que são as gigantes azuis. E a resposta correta é anãs marrons.

Portanto, do total de 8 perguntas, o estudante acertou 6 delas. 


\section{c) Resultados do questionário final de conceitos direcionado aos estudantes}

Neste questionário, os sujeitos não deram retorno nos formulários.

\section{d) Resultados do questionário final direcionado aos estudantes}

Neste questionário apenas I dos sujeitos respondeu e nos enviou o formulário, o outro sujeito não nos deu retorno.

Assim, quanto as questões deste questionário final direcionado aos estudantes, as respostas foram:

I. O preparatório do Projeto Cosmos correspondeu às suas expectativas?

$\mathrm{R}$ - A reposta do estudante foi: "Sim, totalmente".

2. Como você recomendaria o preparatório para o Projeto Cosmos à outras pessoas?

R - A resposta do estudante foi: "Mídias sociais".

3. Qual o seu nível de satisfação a respeito da atuação dos monitores nas aulas?

$\mathrm{R}$ - A resposta do estudante foi: "Alto".

4. Qual o seu nível de satisfação a respeito das aulas do Preparatório do Projeto Cosmos?

$\mathrm{R}$ - A resposta do estudante foi: "Alto".

5. Após participar do Preparatório do Projeto Cosmos, como você estimaria o seu nível de conhecimento a respeito da Astronomia?

$\mathrm{R}$ - A resposta do estudante foi: "Pouco".

6. A experiência de participar do Projeto Cosmos o motivou para a escolha de alguma profissão?

$\mathrm{R}$ - A resposta do estudante foi: "Sim, um pouco".

\section{e) Resultados do questionário direcionado aos coordenadores}

Neste questionário não existiu retorno, pois após o início da pandemia e a nova submissão do comitê de ética, não havia mais coordenador pois o Projeto Cosmos não foi renovado como projeto de extensão no segundo semestre. Entretanto, apesar de não haver como obter os dados requeridos pelo questionário aos coordenadores 
atuais, foi possível recorrer, através da antiga gestão do projeto, um documento de inscrição do Programa de Atividade Curricular de Extensão (PACE) e do site do Projeto Cosmos, correspondente ao primeiro semestre do ano de 2019, que continha quase todas as informações solicitadas no questionário.

Quantos as perguntas do formulário em questão:

I. Como se originou o projeto cosmos?

R - Carlla, a idealizadora do projeto Cosmos, disse no link: http://projetocosmos.gear.host/,

Começou comigo, Carlla, que tinha escrito um projeto de preparatório para a OBA (Olimpíada brasileira de Astronomia e Astronáutica) para dar para a minha antiga escola de ensino médio: A Fundação Nokia. Durante os três anos que estava lá participei da olimpíada, recebi medalhas e também tive a oportunidade de viajar e participar de uma semana de curso em São Paulo, a chamada Jornada Espacial. Como a Astronomia não está na grade regular do ensino médio, acabei estudando muita coisa por conta própria, e pensei que seria legal passar esse conhecimento para os alunos que chegavam à escola, para que quando fossem fazer a olimpíada tivessem um melhor desempenho. Então a diretora aprovou o preparatório e eu acabei chamando alguns amigos, outros viram posts nas redes sociais, gostaram muito e pediram para participar. Realizamos o preparatório e foi uma experiência maravilhosa, os alunos gostaram bastante e ficamos com vontade de fazer de novo e de atingir mais gente. Muitas pessoas, por terem visto os posts, vieram falar comigo pedindo que fossem em outras escolas e achamos muito legal. Nasceu o Projeto Cosmos!"

A participarem das olimpíadas de conhecimento, em especial a OBA, que é um dos focos do projeto.

2. Qual o público-alvo do Projeto Cosmos? Qual o objetivo do projeto cosmos?

$\mathrm{R}$ - Objetivo geral: Discutir e analisar conceitos de Astronomia e Astronáutica, normalmente ausentes da grade curricular dos alunos do ensino fundamental e médio, para que possam ampliar seu entendimento da natureza e seus fenômenos.

Objetivos específicos: Conscientizar sobre a importância das ciências da natureza no dia a dia e no desenvolvimento social e tecnológico da humanidade;

3. Trazer uma abordagem didática e dinâmica para as aulas, com resolução de exercícios e uso de ferramentas de multimídia, criando assim um ambiente que interaja melhor com o aluno; Disponibilizar materiais, listas e indicações de filmes e livros para maior aprofundamento no assunto; incentivar os alunos 
$R$ - Jovens, estudantes do ensino médio ou fundamental e recentemente surgiu a oportunidade de ir em abrigos infantis da cidade. Estamos tentando ser o mais flexível em relação à didática e tentar atender um público de faixa etária ampla.

4. Como funciona o preparatório do Projeto Cosmos?

R - Procedimentos metodológicos: No preparatório das Olimpíadas Brasileiras de Astronomia, os monitores realizam as atividades no colégio em questão, e lecionam as aulas conforme o conteúdo programado. As aulas têm duração média de duas horas e são realizadas por dois monitores. Os recursos utilizados nas aulas constam de conteúdos preparados em slides e no fim do processo de aulas, tempos antes das olimpíadas, são elaborados simulados na instituição de ensino para que os alunos possam praticar seus conhecimentos. Dentro dos materiais utilizados no curso seriam os mais diversos e dinâmicos possíveis, como vídeos, animações, jogos e se o tempo permitir uma experiência prática. $O$ acompanhamento do preparatório também é feito via redes sociais, por meio de um grupo no Facebook, que conta com a participação dos alunos e monitores.

5. Quantas escolas já participaram do Projeto Cosmos?

$\mathrm{R}$ - O Coordenador do Projeto não soube estimar quantas escolas já haviam participado, mas para o primeiro semestre de 2019, a estimativa da quantidade de pessoas a serem atingidas foi de 500 pessoas.

6. Quais as conquistas já alcançadas pelo projeto cosmos?

$\mathrm{R}$ - A criação de um site onde se pode verificar a distância entre os planetas, além da velocidade e seus respectivos tamanhos. Também foi selecionado através de edital para receber apoio da instituição Serrapilhera, participou de uma entrevista para a revista Nova Escola, segundo o portal Ciência na Rua, o Projeto Cosmos foi selecionado para ser apresentado durante o $2^{-}$Simpósio em Atividades de Educação Espacial, que aconteceu entre II e 13 de abril de 2018, em Budapeste, na Hungria. Segundo a revista Galileu, o Projeto Cosmos participou de 25 eventos com atividades em escolas periféricas e comunidades ribeirinhas no interior do estado. A idealizadora do Projeto Cosmos participou do Brazil Conferece at Havard \& MIT 2019, nos Estados Unidos.

7. Quantos participantes já alcançaram medalhas? 
R - Segundo Carlla Vicna, ir alunos de escolas públicas foram medalhistas na OBA.

8. Algum dos participantes já demonstraram interesse em continuar seus estudos nesta área?

R - Sim, além disso, segundo a Carlla Vicna, cerca de 2 mil estudantes foram impactados ao longo dos últimos 4 anos, e ficaram bastantes motivados com esta área.

\section{CONSIDERAÇÕES FINAIS}

Quanto ao nosso objetivo, embora o Projeto Cosmos tenha sofrido paralisação no ano de 2020, mas nossa pesquisa considerou os anos anteriores e, pelos dados coletados, verificamos que o Projeto cosmos teve um impacto muito grande na formação dos estudantes do Ensino médio e fundamental, não só em termo de aprendizagem, mas também de possibilidades de participação em eventos, entrevistas e ganho de medalhas. Quanto a metodologia dos professores do Projeto cosmos, eles ministram aulas teóricas e práticas de uma em uma semana. Quanto aos conceitos apreendidos foram: história sobre Astronomia, Constelações, sistema solar e sistema terra e lua, além de conceitos sobre o Universo e formação das estrelas. Portanto, esperamos que esta pesquisa possa de alguma forma, estimular mais projetos como este em prol do aprendizado de Ciências utilizando-se da interdisciplinaridade que há no estudo da Astronomia.

\section{REFERÊNCIAS}

DE OLIVEIRA, T. C. Reflexões sobre iniciativas de popularização da ciência através de Projetos de Extensão. Disponível em: < https://eventos.set.edu.br >. Acesso em: II.OI.2022

FILHO, A.A.A. Uso de telescópios remotos no ensino da astronomia: da interface na Web à aplicação no estudo do Catálogo Messier e da Lua.2018. Tese (mestrado em astronomia) - Departamento de Física, Universidade Estadual de Feira de Santana, Feira de Santana, 2018. Disponível em: http://tede2.uefs.br:8o8o/handle/tede/573\#preview-linko e acesso em: I8 abr. 2019.

NOGUEIRA, S; CANALLE, J.B.G. Astronomia: fronteira espacial parte I. Brasília: Ministério da Educação, 2009. Disponível em: 
http://portal.mec.gov.br/index.php?option=com_docman\&view =download\&alias $=4$ 232-colecaoexplorandooensino-voliI\&category_slug=marco-2010-pdf\&Itemid=30192 e acesso em: I9 abr. 2019.

SCHMIDT, A. de B. Manual de Técnicas de trabalhos acadêmicos. Osasco: EDIFIEO, 20I4.

PONCHIROLLI, O.; PONCHIROLLI, M. Métodos para a produção do Conhecimento. São Paulo: Atlas, 2012.

SCARINCI, A.; PACCA, J. Um curso de astronomia e as pré-concepções dos alunos. Revista Brasileira de Ensino de Física, v. 28, n. I, p. 89 - 99, (2006). Disponível em: http://www.scielo.br/pdf/rbef/v28nI/ar2v28ni.pdf. Acesso em: 20 jun. 2019.

VICNA, CARLLA; Sobre. Projeto Cosmos, 2or6. Disponível em: http://projetocosmos.gear.host/. Acesso em: 29 set. 2020.

MARCONI, E.; Projeto Cosmos, da Amazônia para o espaço sideral. Ciência na Rua, 20I8. Disponível em: https://ciencianarua.net/da-amazonia-para-o-espacosideral/. Acesso em: 30 set. 2020.

OLIVEIRA, A, J.; Projeto que leva astronomia a escolas públicas é reconhecido na Europa. Revista Galileu, 2018. Disponível em: https://revistagalileu.globo.com/blogs/Luneta/noticia/2018/o4/projeto-que-levaastronomia-escolas-publicas-e-reconhecido-na-europa.html. Acesso em: 30 set. 2020.

Acrítica; Estudante da Ufam é embaixadora do Brasil em conferência de Harvard \& MIT no EUA. Acrítica, 2019. Disponível em: https://www.acritica.com/channels/manaus/news/estudante-da-ufam-eembaixadora-do-brasil-em-conferencia-de-harvard-mit-no-eua. Acesso em: 30 set. 2020.

RODRIGUES, V.M. O fórum de pró-reitores de extensão e sua contribuição no debate sobre a extensão universitária. Revista Educação e Políticas em Debate, v. 4, n.2, 2015.

SERRANO, R.M.S.M. Conceitos de extensão universitária: um diálogo com Paulo Freire. Disponível em: <http://www.prac.ufpb.br/copac/extelar/atividades/discussao/artigos/conceitos_de_ext ensao_universitaria.pdf $>$ Acesso em: o9 fev. 2017. 